\title{
ASO Visual Abstract: Gastric Neuroendocrine Tumors: Reappraisal of Type in Predicting Outcome
}

\author{
Andrew Hanna, $\mathrm{MD}^{1}{ }^{(\mathbb{D})}$, Caroline Kim-Kiselak, $\mathrm{MA}^{2}$, Rebecca Tang, $\mathrm{MD}^{3}$, David C. Metz, $\mathrm{MD}^{4}$, \\ Zhaohai Yang, MD, PhD $^{5}$, Ronald DeMatteo, $\mathrm{MD}^{1}$, Douglas L. Fraker, $\mathrm{MD}^{1}$, and Robert E. Roses, MD ${ }^{1}$ \\ ${ }^{1}$ Department of Surgery, University of Pennsylvania, Philadelphia, PA; ${ }^{2}$ University of Pennsylvania School of Medicine, \\ Philadelphia, PA; ${ }^{3}$ Department of Surgery, Massachusetts General Hospital, Boston, MA; ${ }^{4}$ Department of Medicine, \\ University of Pennsylvania, Philadelphia, PA; ${ }^{5}$ Department of Pathology and Laboratory Medicine, University of \\ Pennsylvania, Philadelphia, PA
}

Type 3 gastric neuroendocrine tumors (GNETs) compared with type 1 GNETs are associated with worse outcomes and often are treated surgically rather than endoscopically. This study (https://doi.org/10.1245/s1043
4-021-10293-7) identified a subset of type 3 GNETs that may be treated more conservatively, similar to the treatment for type 1 GNETs.

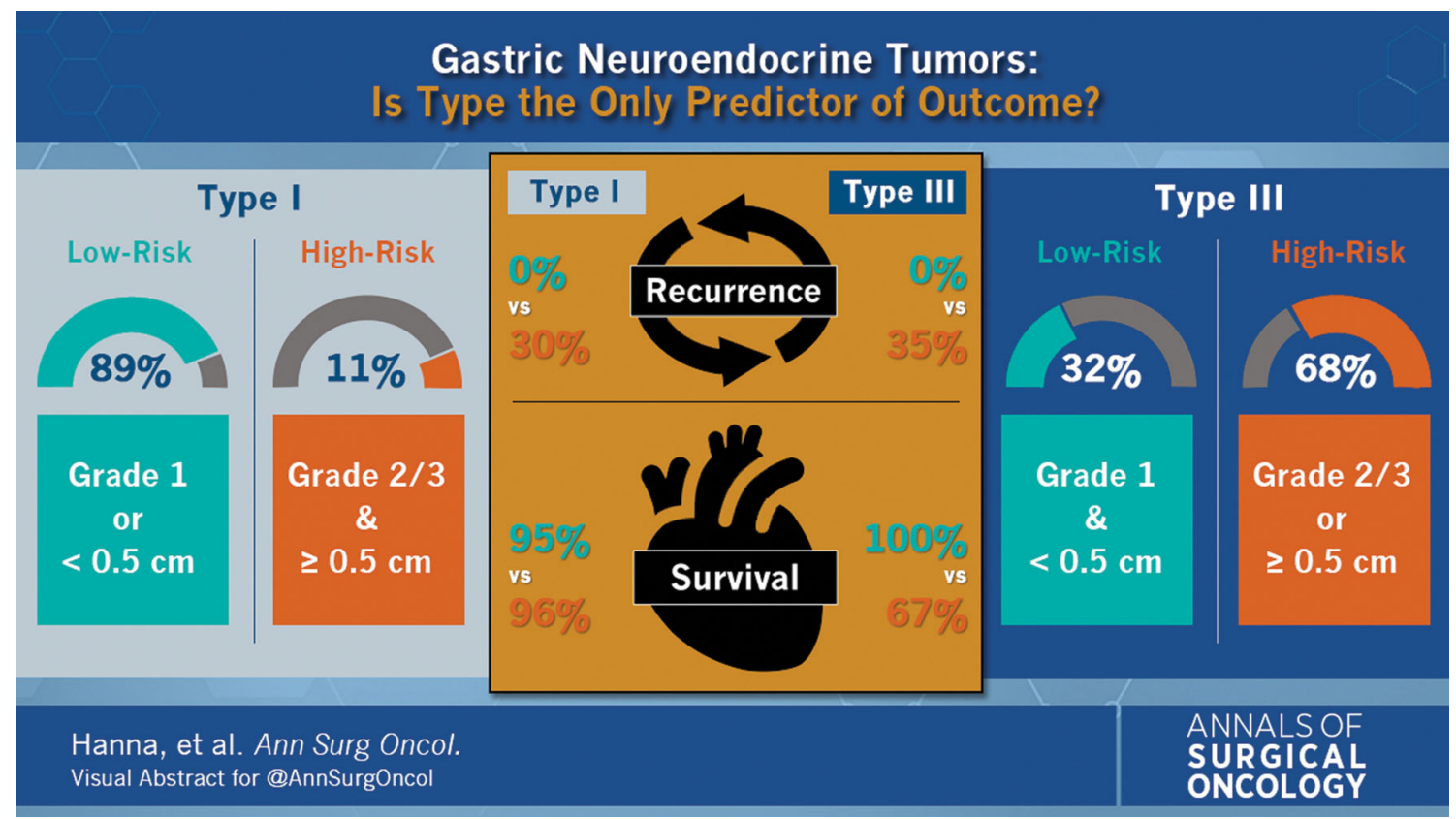

Abstract orally presented at the Society of Surgical Oncology 18 DISCLOSURE David Metz is a consultant for Crinetics and LexMarch 2021 icon. The other authors have no conflicts of interest.

(C) Society of Surgical Oncology 2021

Publisher's Note Springer Nature remains neutral with regard to jurisdictional claims in published maps and institutional affiliations.

First Received: 4 June 2021

Accepted: 14 June 2021;

Published Online: 15 July 2021

A. Hanna, MD

e-mail: andrewnhanna4@gmail.com 